\title{
Nutritional status and associated feeding practices among children aged 6-24 months in a selected community in Sri Lanka: A cross sectional study
}

\author{
Nishani H. Ubeysekara ${ }^{1}$, Renuka Jayathissa ${ }^{2}$, Champa J. Wijesinghe ${ }^{3}$ \\ ${ }^{1}$ Department of Community Medicine, Faculty of Medicine, University of Ruhuna, Matara, Sri Lanka \\ ${ }^{2}$ Nutrition Division, Medical Research Institute, Colombo, Sri Lanka \\ ${ }^{3}$ Department of Community Medicine, Faculty of Medicine, University of Ruhuna, Matara ,Sri Lanka \\ Email address: \\ nishaniubaysekara@yahoo.com (N. H. Ubeysekara), cjw@med.ruh.ac.lk (C. J. Wijesinghe)
}

\section{To cite this article:}

Nishani H. Ubeysekara, Renuka Jayathissa, Champa J. Wijesinghe. Nutritional Status and Associated Feeding Practices among Children Aged 6-24 Months in a Selected Community in Sri Lanka: A Cross Sectional Study. European Journal of Preventive Medicine. Special Issue: New Frontiers of Public Health from the Pearl of Indian Ocean, Sri Lanka. Vol. 3, No. 2-1, 2015, pp. 15-23.

doi: 10.11648/j.ejpm.s.2015030201.14

\begin{abstract}
Background: In Sri Lanka, nutritional indicators are static compared to other health indicators. Under nutrition among children less than five years remains a common public health problem. Poor nutritional status of children is associated with various factors which are preventable. Purpose of this study was to determine the nutritional status of children aged 6-24 months in a selected health unit area and to describe the associated feeding practices. Methods and materials: A cross sectional study was conducted among mothers of 428 children attending 24 randomly selected field weighing posts in Akuressa health division, for routine growth monitoring. Nutritional status of the children was assessed with anthropometric measurements and WHO growth charts. Other data were collected using an interviewer-administered questionnaire. Results: Prevalence of stunting, wasting and underweight in the sample was $17 \%, 17.1 \%$ and $21.3 \%$ respectively. Mean age of exclusive breast feeding was 5.8 months and prevalence of exclusive breast feeding for 6 months was 88.8\%. Mean age of starting complimentary feeding was 6 months and majority (75.5\%) started semisolids as the first food. A majority (75.8\%) of the mothers practiced proper feeding during infections. Wasting was significantly associated with male gender $(\mathrm{p}<0.01)$, increasing age of the child $(\mathrm{p}<0.05)$ and late introduction of fat and oils into the diet (after 8 months of age) $(p<0.001)$. Underweight was associated with male gender $(\mathrm{p}<0.001)$, increasing age $(\mathrm{p}<0.05)$ and late introduction of fat and oils into diet (after 8 months of age) $(p<0.05)$. Stunting was only associated with male gender $(p<0.05)$. Conclusion: Under nutrition among children is common in this age group. Some of the feeding practices are associated with poor nutritional status and these practices should be improved with effective interventions.
\end{abstract}

Keywords: Stunting, Wasting, Underweight, Sri Lanka

\section{Introduction}

Every year, ten and half million children under 5 years of age die worldwide and $98 \%$ of these deaths occur in developing countries [1]. Fifty percent of child deaths in developing countries are related to malnutrition potentiating effects[2].The vast majority of underweight children live in developing regions, mainly in Asia and Africa[3]. According to WHO global database on Child Growth and Malnutritionvery high levels of childhood underweight were found in 12 African countries and 13 Asian countries including Sri Lanka [3]. Sri Lanka has achieved targets in reducing the number of children who die from preventable causes [4]. The country is on track to achieve Millennium Development Goals related to child mortality, maternal health and HIV and AIDS. Under five mortality currently stands at 15 deaths per 1,000 live births, almost all children are immunized, HIV prevalence is under $0.1 \%$ and the maternal mortality ratio is 33.4 per 100,000 birthsin 2008 [4]. Though current Sri Lankan child health indicators are in par with some developed countries, improvement of nutritional status of children under five years of age is very slow and the 
country was unable to achieve its goals in reducing underweight, stunting and wasting [5]. According to the Demographic and Health Survey (DHS) 2006/07, prevalence of stunting was $18 \%$, wasting was $15 \%$ and underweight was $22 \%$ in Sri Lanka [6].WHO, UNICEF, World Bank joint estimates reported the prevalence of stunting, wasting and underweight, $19 \%, 12 \%$ and $22 \%$ respectively in 2009[7] Factors responsible for malnutrition particularly in children under five years of age include birth weight, birth interval, parity, age $[8,9,10]$ and sex of child [11], socio economic conditions $[8,13,14]$, living standards, water and sanitation, food intake, weaning practices and mother's education [8, 15].However, dietary inadequacy is certainly the basic cause of malnutrition in preschool age children, and many of the above identified factors directly or indirectly contributes to the incidence of malnutrition[15].Both chronic and acute malnutrition starts to develop during the weaning period and rise sharply in the second year of life[15]. In addition, diarrheal diseases are identified as a common cause of malnutrition in this age group[15].

Feeding practices in early life are important as they determine health and development of an entire lifetime [16]. In the growth and development of a child, the impact of feeding practices is more significant than lack of food [17]. In 1994 the WHO recommended that exclusive breast feeding can meet all the infant's energy and nutrient requirement for at least six months and at the age of six months thought to be appropriate for commencing complimentary feeding. WHO \& UNICEF (1995) stated that breast feeding should be continued with the complimentary foods at least for the first two years of life. Feeding of the child during childhood infections especially diarrhea is important because inadequate feeding during illnesses increases the risk of under nutrition of children [18].

Inappropriate feeding during early childhood, due to lack of knowledge of mothers about appropriate foods stands out as a major determinant of childhood malnutrition [19]. Sinceunder nutrition is a major public health problem in Sri Lanka which mainly affects children under 5 years of age and also the main cause for morbidity and mortality of children in this age group, evidence on nutritional status and its associated factors and the feeding practicesare essential for planning proper interventions to overcome this challenge. The aim of this study was to determine the nutritional status of children aged 6-24 months in health division Akuressa in Southern Sri Lanka, the common feeding practices and the association of nutritional status with these feeding practices.

\section{Methodology}

A cross sectional study was conducted among 428 motherchild pairs living in Akuressa health division in Matara district, Sri Lanka. Study participants were selected using cluster sampling and field weighing post (FWP) was identified as a cluster.Due to logistic issues, 24 (out of 72) clusters were randomly selected and 18 children in the age group of 6 months to 2 years attending selected FWP for regular growth monitoring and their mothers were recruited as study subjects. Average number of children (from all age groups) registered in each FWP was 50. From each FWP, 18 eligible children were selected and if more than 18 children attended on the day of data collection, required number of children was randomly selected from the register. Children who have congenital abnormalities (ex: congenital heart diseases, congenital problems in palate or the gastro intestinal tract) and those suffering from chronic illnesses were excluded from the study.

Two study instruments were used for data collection. A data sheet was used to record anthropometric measurements (height/length and the weight) of the child. A pretested, interviewer-administered questionnaire was used to collect data on basic characteristics of the mother, child and the feeding practices. Feeding practices related to nutritional status such as exclusive breast feeding, duration of partial breast feeding, formula feeding, age of starting complimentary feeding, type of food first introduced, age of introducing leafy vegetables, oils and food items of animal origin, method of giving feeds and feeding during illnesses were collected. Trained health volunteers with previous experience of working in field weighing posts and in field clinics conducted the interviews. Weight and the length were measured by a Public Health Midwife and a volunteer, who were trained on these procedures and also on calibration of the instruments. Standard instruments were used to take the anthropometric measurements.

Three indicators were used to assess nutritional status by using anthropometric measurements; weight for age, height/length for age and weight for height. Cut off of these measurements to determine the nutritional status was based on the WHO reference values for children 6-24 months. The measurements of weight for age, height/length for age and weight for height, that are falling below -2 standard deviations (SD) from the median value for the reference population was considered as underweight, stunting and wastingrespectively.

Data was analyzed using SPSS 15.0 version. Descriptive statistics including mean, standard deviation were obtained. All analysis was done with the test of significance ( $p$ value, Chi-square). Ethical clearance for the study was obtained from institutional review board of faculty of medicine, university of Sri Jayawardenepura, Sri Lanka.

\section{Results}

Response rate of the study was $100 \%$. The mean age of the mothers participated in the study was $30.4(\mathrm{SD} \pm 6.2)$ years and that of children was $14.8(\mathrm{SD} \pm 6.0)$ months. Majority (98.8\%) of mothers were Sinhalese. Over $30 \%$ of the mothers have completed advance level examination. Only $8.4 \%$ mothers were employed. Approximately $25 \%$ of families had a low monthly income. Table 1 describes the basic characteristics of the study subjects and the nutritional status of the children.

Of the children $52.1 \%$ were males and $11.4 \%$ had low 
birth weight $(<2500 \mathrm{~g})$. The majority of children $(98.8 \%)$ have had age appropriate immunization.

Nutritional status of children was classified according to the WHO Growth standards (WHO 2005). The most prevalent form of under-nutrition was underweight (21\%) and the prevalence of stunting and wasting in the study sample was $17.3 \%$ and $17.1 \%$ respectively (Table 1 ). Less than $1 \%$ of the children were overweight / obese according to the growth standards.

Table 1. Basic characteristics of the study sample and the nutritional status of children

\begin{tabular}{lll}
\hline Basic characteristic & Number(428) & \% \\
\hline Age of the child (in months) & 161 & 37.7 \\
$6-11$ & 100 & 23.4 \\
$12-17$ & 167 & 38.9 \\
$18-24$ & & \\
Mean age 14.8SD \pm 6 & & \\
Sex & 223 & 52.1 \\
Male & 205 & 47.9 \\
Female & & \\
Birth Order & 190 & 44.4 \\
1 & 151 & 35.3 \\
2 & 61 & 14.3 \\
3 & 24 & 5.6 \\
4 & 2 & 0.5 \\
$>4$ & & \\
Birth weight & 49 & 11.4 \\
$<2500$ g & 379 & 88.6 \\
$\geq 2500$ g & & \\
Immunization & 427 & 98.8 \\
Age appropriate & 1 & 1.2 \\
Not age appropriate & 153 & 64.3 \\
Nutritional status*Normal & 90 & 21.0 \\
Under weight & 74 & 17.3 \\
Stunting & 73 & 0.7 \\
Wasting & 3 & \\
Over weight & & \\
\hline
\end{tabular}

\subsection{Feeding Practices Adopted by Mothers}

The distribution ofmilk feeding practices in the sample is described in Table 2.

Table 2. Feeding practices adopted by the mothers

\begin{tabular}{lll}
\hline $\begin{array}{l}\text { Exclusive Breast feeding duration (No. of } \\
\text { months) }\end{array}$ & Number (n=428) & \% \\
\hline 1 & 2 & 0.5 \\
3 & 14 & 3.3 \\
4 & 23 & 5.4 \\
5 & 7 & 1.6 \\
6 & 377 & 88.1 \\
7 & 5 & 1.2 \\
Current Breast Feeding & & \\
Yes & 407 & 95.1 \\
No & 21 & 4.9 \\
Mean duration of current breast feeding & & \\
14.5 months & $S D \pm 4.56$ & \\
Formula feeding & & 18.5 \\
Yes & 79 & 81.3 \\
No & 348 & \\
Reason for starting formula & & 14.1 \\
1 Inadequate breast milk & 11 & 25.6 \\
2 Reduced weight & 20 & 23.1 \\
3 working mother & 18 & \\
\hline
\end{tabular}

\begin{tabular}{lll}
\hline 4 Child not eating & 14 & 16.7 \\
5 Mother became pregnant & 5 & 6.4 \\
6 other & 11 & 14.1 \\
\hline
\end{tabular}

Approximately $88 \%$ of mothers $(n=377)$ breast fed their children exclusively for 6 months and $95 \%$ of the mothers $(n=407)$ were breast feeding their children at the time of the study. The majority $(81.5 \%: \mathrm{n}=348)$ had not introduced formula milk for their babies before 12 months of age. Of the mothers who started formula milk, $25 \%$ did so due to poor weight gain of the child. Other reasons were working mother (23.1\%: $\mathrm{n}=18)$, inadequate breast milk $(14.1 \%$; $\mathrm{n}=11)$, child is not eating $(16.7 \% ; n=14)$, mother became pregnant $(6.4 \%$; $\mathrm{n}=5$ ).Approximately $14 \%$ of the mothers who introduced formula milk to their infants $(14.1 \% ; n=11)$ reported that they were advised to do so by a medical personnel or relatives etc.

Proportion of mothers started complimentary foods for their children at the age of six months, was $75.2 \%(n=322)$. However none of them started complimentary feeding before 4 months of age. The majority of the mothers $(99.5 \% ; n=426)$ fed their children with the cup and the spoon, according to the recommendations. Mashed rice was the first food given to most children $(75.5 \%, \mathrm{n}=323)$ and the rest were given rice cunjee. Mean age of introducing food of animal origin into child's diet was 6.67( $\mathrm{SD} \pm 2.3)$ months. Introduction of animal origin food, distribution of age and the type is described in Table 3.

Table 3. Age of introduction of animal origin foods to the children's diet

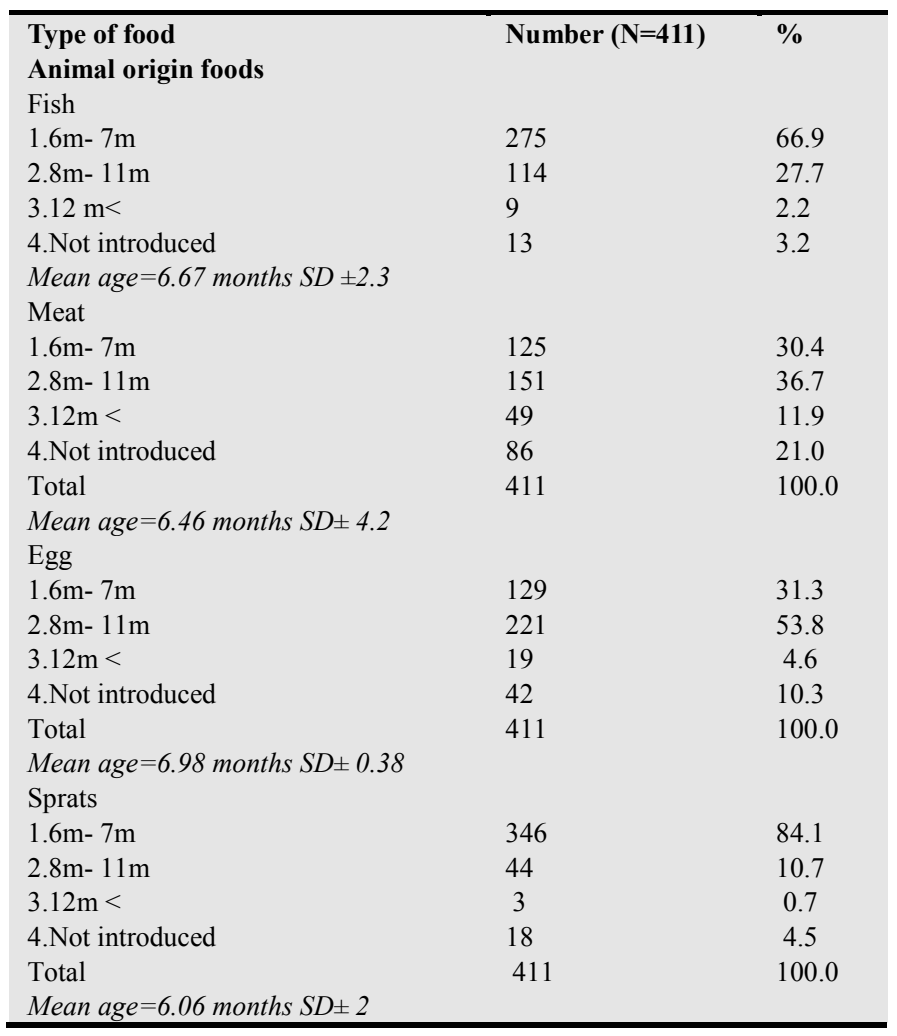

Oils were introduced into child's diet at the age of 6-7 months by nearly half of the mothers in the sample, however, oils were not started at the age of 12 months by $11.2 \%(n=48)$ 
of mothers. Mean age of introduction of oils was 6.95 months.

Respiratory tract infections were the commonest type $(30.8 \% ; n=132)$ of infection reported among the children in this sample, followed by gastroenteritis $(5.6 \%, n=24)$. A history of recurrent illnesses was observed in $41.6 \%$. A majority $(75.8 \% ; n=135)$ of children were properly fed by the mothers during infections (with adequate water, normal diet and with continuous breast feeding).

\subsection{Nutritional Status and Associated Factors}

The prevalence of stunting, wasting and underweight were significantly higher among boys than among girls $(21.1 \%$, $22.4 \%$ and $31.4 \%$ versus $13.2 \%, 11.2 \%$ and $9.8 \%$ respectively, $\mathrm{p}<0.05)$. The highest prevalence of stunting (18.8\%), wasting (26.5\%) and underweight (28.2\%) was found in18-24months age group. Prevalence of wasting and underweight increased significantly with the increasing age $(p<0.05)$. Stunting and underweight was commoner in lower income category compared to the higher income groups, however the relationship between income and the nutritional status was not statistically significant $(\mathrm{p}>0.05)$. A higher prevalence of wasting, underweight and stunting was observed among children of unemployed mothers than the employed mothers.

Duration of exclusive breast feeding, duration of partial breast feeding and introduction of formula milk had no significant relationship with stunting, wasting or underweight $(\mathrm{p}>0.05)$. Table 4 shows the association between nutritional status and the milk feeding practices.

Stunting and underweight were common in children who received complementary food before completing 6 months. There was no statistically significant relationship between the age of introduction of complementary feeding and the nutritional status (stunting, wasting or under-weight) $(\mathrm{p}>0.05)$. Wasting and underweight was significantly higher in children those who were not introduced oils before 12 months of age $(p<0.05)$ But late introduction of oily foods was not associated with stunting. ( $p>0.05)$.

There was no statistically significant relationship between the introduction of animal origin foods to child's diet and the stunting and under-weight $(p>0.05)$. But wasting was significantly high in those who were not received animal origin foods $(\mathrm{p}<0.05)$.

Table 4. Nutritional status in relation to milk feeding practices

\begin{tabular}{|c|c|c|c|c|c|c|}
\hline Feeding & Stunting & & Wasting & & under & weight \\
\hline \multirow{2}{*}{ Practices } & Yes & No & Yes & No & Yes & No \\
\hline & No. $(\%)$ & No. (\%) & No. (\%) & No. $(\%)$ & No. (\%) & No. $(\%)$ \\
\hline \multicolumn{7}{|c|}{ Excusive breast feeding } \\
\hline \multirow{2}{*}{$<6$ months } & 5 & 39 & 6 & 38 & 8 & 36 \\
\hline & (11.4) & $(88.6)$ & (13.6) & (86.4) & $(18.2)$ & $(81.8)$ \\
\hline \multirow{3}{*}{$\geq 6$ months } & 69 & 315 & 67 & 317 & 82 & 302 \\
\hline & (18) & (82) & $(17.4)$ & $(82.6)$ & (21.4) & $(78.6)$ \\
\hline & $x^{2}=1.2$ & & $x^{2}=0.40$ & & $x^{2}=0.24$ & \\
\hline \multirow[t]{2}{*}{ Statistics } & $\mathrm{df}=1$ & & $\mathrm{df}=1$ & & $\mathrm{df}=1$ & \\
\hline & $\mathrm{P}=0.28$ & & $\mathrm{P}=0.52$ & & $\mathrm{P}=0.62$ & \\
\hline Partial Breast & Feeding & & & & & \\
\hline \multirow{2}{*}{ Continued } & 73 & 334 & 69 & 338 & 87 & 320 \\
\hline & (17.9) & $(82.1)$ & (17) & (83) & $(21.4)$ & $(78.6)$ \\
\hline \multirow{3}{*}{ Not continued } & 1 & 20 & 4 & 17 & 3 & 18 \\
\hline & (4.8) & $(95.2)$ & (19) & (81) & $(14.3)$ & $(85.7)$ \\
\hline & $x^{2}=2.4$ & & $x^{2}=0.062$ & & $x^{2}=0.6$ & \\
\hline \multirow[t]{2}{*}{ Statistics } & $\mathrm{df}=1$ & & $\mathrm{df}=1$ & & $\mathrm{df}=1$ & \\
\hline & $\mathrm{P}=0.12$ & & $\mathrm{P}=0.80$ & & $\mathrm{P}=0.43$ & \\
\hline \multicolumn{7}{|c|}{ Formula feeding } \\
\hline \multirow{2}{*}{ Not started } & 66 & 283 & 56 & 293 & 79 & 270 \\
\hline & (18.9) & (81.1) & (16) & (84) & (22.6) & (77.4) \\
\hline \multirow{5}{*}{ Started } & 8 & 71 & 17 & 62 & 11 & 68 \\
\hline & (10.1) & (89.9) & $(21.5)$ & (78.5) & (13.9) & $(86.1)$ \\
\hline & $x^{2}=3.47$ & & $x^{2}=1.36$ & & $x^{2}=2.9$ & \\
\hline & $\mathrm{df}=1$ & & $\mathrm{df}=1$ & & $\mathrm{df}=1$ & \\
\hline & $\mathrm{P}=0.07$ & & $\mathrm{P}=0.24$ & & $\mathrm{P}=0.09$ & \\
\hline
\end{tabular}


Table 5 shows the association between nutritional status and the complimentary feeding practices

Table 5. Nutritional status in relation to complimentary feeding practices

\begin{tabular}{|c|c|c|c|c|c|c|}
\hline Feeding & Stunting & & Wasting & & under & weight \\
\hline \multirow{2}{*}{ Practices } & Yes & No & Yes & No & Yes & No \\
\hline & No. (\%) & No. (\%) & No. (\%) & No. (\%) & No. (\%) & No. $(\%)$ \\
\hline \multicolumn{7}{|c|}{ Complementaryfeeding } \\
\hline$<6$ months & $\begin{array}{l}8 \\
(17.8)\end{array}$ & $\begin{array}{l}37 \\
(82.2)\end{array}$ & $\begin{array}{l}7 \\
(15.6)\end{array}$ & $\begin{array}{l}38 \\
(84.4)\end{array}$ & $\begin{array}{l}10 \\
(22.2)\end{array}$ & $\begin{array}{l}35 \\
(77.8)\end{array}$ \\
\hline \multirow[t]{4}{*}{$\geq 6$ months } & $\begin{array}{l}66 \\
(17.2)\end{array}$ & $\begin{array}{l}317 \\
(82.8)\end{array}$ & $\begin{array}{l}66 \\
(17.2)\end{array}$ & $\begin{array}{l}317 \\
(82.8)\end{array}$ & $\begin{array}{l}80 \\
(20.9)\end{array}$ & $\begin{array}{l}303 \\
(79.1)\end{array}$ \\
\hline & $\chi^{2}=0.008$ & & $x^{2}=1.2$ & & $x^{2}=0.43$ & \\
\hline & $\mathrm{df}=1$ & & $\mathrm{df}=1$ & & $\mathrm{df}=1$ & \\
\hline & $\mathrm{P}=1$ & & $\mathrm{P}=0.28$ & & $\mathrm{P}=0.83$ & \\
\hline \multicolumn{7}{|c|}{ Animal origin foods } \\
\hline Started & $\begin{array}{l}72 \\
(17.5)\end{array}$ & $\begin{array}{l}339 \\
(82.5)\end{array}$ & $\begin{array}{l}64 \\
(15.6)\end{array}$ & $\begin{array}{l}347 \\
(84.4)\end{array}$ & $\begin{array}{l}87 \\
(21.2)\end{array}$ & $\begin{array}{l}324 \\
(78.8)\end{array}$ \\
\hline \multirow[t]{4}{*}{ Not started } & $\begin{array}{l}2 \\
(11.8)\end{array}$ & $\begin{array}{l}15 \\
(88.2)\end{array}$ & $\begin{array}{l}9 \\
(52.9)\end{array}$ & $\begin{array}{l}8 \\
(47.1)\end{array}$ & $\begin{array}{l}3 \\
(17.6)\end{array}$ & $\begin{array}{l}14 \\
(82.4)\end{array}$ \\
\hline & $x^{2}=0.0,37$ & & $x^{2}=16.1$ & & $x^{2}=0.12$ & \\
\hline & $\mathrm{df}=1$ & & $\mathrm{df}=1$ & & $\mathrm{df}=1$ & \\
\hline & $\mathrm{P}=0.7$ & & $\mathrm{P}=0.07$ & & $\mathrm{P}=1$ & \\
\hline \multicolumn{7}{|l|}{ Adding oils } \\
\hline Added & $\begin{array}{l}59 \\
(17.2)\end{array}$ & $\begin{array}{l}284 \\
(82.8)\end{array}$ & $\begin{array}{l}45 \\
(13.1)\end{array}$ & $\begin{array}{l}298 \\
(86.9)\end{array}$ & $\begin{array}{l}63 \\
(18.4)\end{array}$ & $\begin{array}{l}280 \\
(81.6)\end{array}$ \\
\hline \multirow[t]{4}{*}{ Not added } & $\begin{array}{l}74 \\
(17.3)\end{array}$ & $354(82.7)$ & $\begin{array}{l}28 \\
(32.9)\end{array}$ & $\begin{array}{l}57 \\
(67.1)\end{array}$ & $\begin{array}{l}27 \\
(31.8)\end{array}$ & $\begin{array}{l}58 \\
(68.2)\end{array}$ \\
\hline & $x^{2}=0.09$ & & $x^{2}=18.9$ & & $\chi^{2}=7.3$ & \\
\hline & $\mathrm{df}=1$ & & $\mathrm{df}=1$ & & $\mathrm{df}=1$ & \\
\hline & $\mathrm{P}=1$ & & $\mathrm{P}=0.000$ & & $\mathrm{P}=0.01$ & \\
\hline
\end{tabular}

\section{Discussion}

This was a descriptive cross sectional study planned to provide baseline data on existing situation and the magnitude of the child nutritional status and feeding practices adopted by the mothers, for planning of interventions to improve the nutritional status of children. One of the health divisions in southern part of Sri Lanka was selected as the study setting and it had mixed population structure (semi urban, rural and estate). Therefor the findings of the study are more likely to reflect the nutritional status of children and practices of majority of mothers in the rural and suburban areas of the country. To determine the nutritional status of the children six months to two years of age, randomly selected sample was taken from the Field Weighing Posts (FWP) where the almost $99 \%$ children of the area were registered for weighing. This made the study a truly representative one and ensured valid application of the findings to the health division.

Main objectives of this study was to determine the nutritional status of the selected children of 6 months to 2 years of age, to describe the feeding practices adopted by the mothers of these children and to find out the association between nutritional status and the feeding practices. Nutritional status was interpreted as stunting, wasting and underweight (height for age, weight for height and weight for age were $<-2 \mathrm{SD}$ ) in this study.According to the results of this study prevalence of underweight, stunting and wasting were $21.3 \%, 17.3 \%$ and $17.1 \%$ respectively. According to the last Sri Lankan DHS survey (2006/07) among under 5 children proportion of underweight was $22 \%$, stunting was $18 \%$ and the wasting was $14 \%$ at national level [5]. Present study results shows similarities to national figures in 2006but wasting was higher in present study. Prevalence of stunting in 2009 in Sri Lanka according to the WHO, UNICEF joined datawas $19 \%$ [7] and it was higher than the present study. Minor differences that can be observed could be due to the differences in age ranges between studies (present study gives prevalence under 2 years of age) and it should be noted that national figures were for the whole country. According to another study done in Sri Lanka among displaced children in North and east showed proportion of stunting, wasting and underweight was $22.8 \%, 18.3 \%$ and $29.5 \%$ respectively[20] and these higher values comparedto present study can be due to the different socioeconomic background of two study populations.

When comparing the present study results with the global data, according to the UNICEF (2013), global prevalence of stunting, underweight and wasting was $26 \%, 16 \%$ and $11 \%$ 
respectively and global prevalence of underweight was higher compared to present study and other indicators were lower than the present study. In South East Asia (SEA) region in under 5 years of age, regional prevalence of stunting, underweight and wasting was $39 \%, 16 \%$ and $16 \%$ respectively [21].The prevalence of underweight in present study was lower compared to the prevalence of SEA region but the prevalence of wasting and stunting showed similar to regional figures.

According to the present study the highest prevalence of stunting (18.8\%), wasting (26.5\%) and underweight (28.2\%) was found in 18-24months age group. wasting and underweight has increased with the increasing age and this pattern is statistically significant. The results of this study cannot bedirectly compared with that of DHS Sri Lanka (2006) findings where the stunting was high in $24-36$ months of age, wasting was highest in 18-23 months age group and underweight was high in 24-35 months age group [6]. Study done in another health division in same province showed similar pattern of increasing the under-nutrition with increasing age of children [22].Study done in in Northern Provinceof Sri Lanka showed similar pattern to the present study in increasing Stunting and wasting up to the age of 3647 months but underweight was not showed that pattern [10].

According to the present study the prevalence of stunting, wasting and underweight of boys were higher than girls. This observation is statistically significant $(p<0.05)$. The DHS survey 2006 also showed same relationship between sex and the nutritional indicators, where all three indicators stunting, wasting and underweight were high in males and a relationship between sex and nutritional indicators. But another study done in the Southern part of Sri Lanka showed no significant difference in nutritional status between boys and girls. The studies conducted in Bangladesh[9] and Jamaica[10] showed that the girls were having relatively poor nutritional status than boys. Differences in socio economic back ground between Sri Lanka and the above countries could be the reason for that.

Present study showed declining of all three indicators with increasing levels of education of the mother and similar relationship was revealed by other two studies done in Sri Lanka: in Sothern province[22] and in Northern province [20].Poor nutritional status was observed among children with unemployed mothers than the employed mothers in the present study and same relationship was shown by another study done on determinants of nutritional status, in Sri Lanka among preschool children [13]. According to the present study stunting $(17.5 \%)$ and underweight $(22.3 \%)$ was higher in lower income category (income $<$ Rs 10000) compared to the higher income groups and similarly low income was found to be a contributory factor for malnutrition in studies done in Sri Lanka[13]. The results indicate the association between lower income and poor nutritional status.

Considering the feeding practices adopted by the mothers, majority (88.1\%) of the babies exclusively breast fed for six months. Compared to DHS survey 2006 (76\% exclusive breast fed up to 6 months) proportion of breast feeding in present study was high. According to the results of a cross sectional descriptive study which was carried out at Boralasgamuwa MOH area in 2004 showed exclusive breast feeding rate at four months and beyond was $52 \%$.Only $3.6 \%$ being exclusively breast fed for five and six months [13]. The proportion of exclusive breast feeding was improved to present level in Sri Lanka after introducing WHO recommendations of six months exclusive breast feeding in the country and with the effort of the public health field staff in promoting breast feeding. Even after introduction of complimentary feeding, most mothers continued breast feeding during first two years. The results of present study showed a majority (95.1\%) of mothers continued breast feeding at the time of the interview and that was similar to a the DHS 2006 data ( $91 \%$ continued breast feeding up to 12 months) and to the study donein the dry Zone of Sri Lanka, where $94.7 \%$ mothers continue breast feeding at 9 months and $93.5 \%$ at 12 months. Exclusive breast feeding prevalence in developing countries was $39 \%$ and in SEA was $45 \%$ in 2010 [24] and when comparing the data with other countries according to the UNICEF statistics exclusive breast feeding rates were low most of the SEA countries (India, Nepal and Maldives were $46 \%, \quad 70 \%$ and $48 \%$ respectively) [21].According to the present study no statistically significant relationship was found between nutritional status and the duration of exclusive breast feeding for 6 months duration. Study done in Honduras where low income primi parae who had breast fed for four months as well as mothers of infants whose birth weight 1.5 to $2.5 \mathrm{Kg}$ showed no significance differences in weight or length gain between those fed exclusively on breast milk for six months and those fed complimentary feeds plus breast feeding during 4-6 months period[18].In the present study prevalence of formula milk usage before 12 months was only $18.5 \%$.According to a study done in Sri Lanka, prevalence of formula usage was $28 \%$ and formula milk introduction at 3 months was $55 \%$ with mean age was 4 months[26].Present study shows high exclusive breast feeding prevalence and less prevalence in starting milk formulas, may be because of strengthened public health advices and due to banding of formula milk advertising in the country.

According to the present study majority of mothers (75.2\%) started complementary foods at the age of 6 months.5.1\% started at the age of 4 months and $4 \%$ started at the age of 5 months. Mean age of starting complementary feeding was 6 months and $\mathrm{SD} \pm 0.68$. According to the DHS survey report (2002), nearly three fourth of infants were receiving supplementary foods in addition to the breast milk. Semi solids are started around four to five months and solid food increases thereafter. It is $29.7 \%$ at $4-5$ months, $60.5 \%$ at $6-7$ months and $74.6 \%$ at $8-9$ months respectively[6]. Although WHO recommended the age of starting of complementary foods as 6 months in1994, the feeding practices changed slowly with time. This difference could be due to the changes in feeding practices in 2002 and at present. According to the UNICEF statistics most of the African countries introduced semisolids and solids at the age of 6-8 months (Ghana 75\%, 
Malawi 86\%) but rates were low in Asian countries compared to Sri Lanka (India 56\%, Nepal 66\%)[25].Though WHO recommended to start complimentary food at the completion of 6 months differences of starting age of complimentary feeding in various countries could be the reason for observed difference in rates. Types of complementary foods given vary with the cultural and socioeconomic factors. Although complementary feeding was started at the correct time, level of nutrition depend on the quality and the quantity of foods given and frequency of meals. Present study a majority $(75.5 \%)$ started mashed rice and $18.9 \%$ started rice cunjee as the first food. But according to DHS survey 2006 one third of children started receiving cunjee on a regular basis[6]. Present study shows improvement of age of starting complementary foods and first food from cunjee to mashed rice and that could be due to the nutritional advices given by the public health staff and due to the advices givenin Child Health Development Record and also can be due to improvement in maternal education level.

Animalorigin foods should be added to child's diet at the age of $6 \mathrm{~m}$ to $7 \mathrm{~m}$ according to the WHO recommendation[27]. According to the present study only $30.4 \%$ introduced meat, $31.3 \%$ eggs and $66.9 \%$ fish, at the age of $6-7$ months. But $95 \%$ mothers introduced animal origin foods before the age of 12 months and mean ages of introducing fish, meat, eggs and sprats were $6.7,6.5,6.9$ and 6.1 months respectively. Present study shows an improvement in the age of starting of animal foods compared to the DHS 2006 data where the proportion of introducing animal origin foods were $67.2 \%$, in the age group of 6-23 months[6]. Introduction of eggs was delayed compared to other animal foods and age of introduction of animal origin foods was not significantly related with the nutritional status. Mean age of starting leafy vegetables was 6 months and the oils were 6.7 months according to the present study and proportion of mothers started leafy vegetables at the age of 6-7 months was $96 \%$ and oils were $51.2 \%$. Most of the mothers were reluctant to add oils into child's diet when they start complimentary feeding. Late introduction of oils had a statistically significant relationship with the nutritional status.

According to the present study $99.5 \%$ used cup and spoon for feeding instead of bottle and teat. Similarly a cross sectional descriptive study done at peri-urban clinics (Boralasgamuwa area) 1n 2005on feeding practices of mothers showed that majority of the mothers use cup and spoon when giving complementary foods[23]. Inpresent study $41.4 \%$ of children have got recurrent infections and from those who hadinfections, $52.6 \%$ were respiratory tract infections and $9 \%$ were gastroenteritis. The studies conducted in Jordan [28], in Brazil [29] showed that frequent episodes of diarrhea as well as respiratory infections were proximate determinants of malnutrition. Study done in Sri Lanka it was found that incidence of diarrhea and respiratory infections were common in underweight children [30] while another study revealed that becomingill or having diarrhea and fever were not associated with malnutrition[31].Present study revealed similar results, respiratorytract infections was commonest and the children were fed properly during infections. Childhood infections were not significantly associated with poor nutritional status. The reason could be the proper feeding practices during infections.

According to the present study duration of exclusive breast feeding, duration of partial breast feeding, introduction of formula feeding, age of starting complimentary foods, type of food started first and introduction of animal origin foods, leafy vegetables were not significantly related to the nutritional status but gender of the child, age of the child and late introduction (after 12 months) of oils in to the diet showed significant relationship with the nutritional status of children. According to the study done in Ethiopia educational level, occupation of mother, parity and having ANC follow up were found to be independent predictors of timely initiation of complementary feeding[32]. Another study revealed maternal age, child age andkeeping livestock were found significantly associated with early introduction of complementary feeding[33]. Differences of associated factors of nutritional status between countries could be due to the disparities in socio economic status, literacy level of females and the cultural conditions.

\section{Conclusion}

Study shows high prevalence of all nutritional indicators. These figures showed similarity with the national figures but wasting was higher than the national level. All three nutritional indicators were significantly higher in males than the females concluded that the male children are having higher risk of developing under nutrition. The highest prevalence of all nutritional indicators was found in1824 months age group. Wasting and underweight has increased with the increasing age. Stunting and underweight was higher in lower income category (income $<$ Rs10000). Higher prevalence of wasting, underweight and stunting was observed among children with unemployed mothers than the employed mothers. Under-nutrition is common in low socio economic conditions.

Exclusive breast feeding was continued for 6 months by majority of mothers, mean age of breast feeding was 5.8 months that indicated the successfulness of the breast feeding promotion program in Sri Lanka. But Still because of various reasons mothers starts formula milk for their babies before the child's sixth month, commonest reason for starting formula milk was the reduced weight gain of the child.

The improvement in introducing semisolid foods in proper time can be observed in this study but the massages should be strengthened further to motivate mothers to start semisolids at proper age. Introduction of animal origin foods was satisfactory but mean age of introduction was later (6.67) than the recommended (6 months) by the child health program in Sri Lanka. Proportion of mothers not introduced meat was relatively higher than fish and sprats. Most mothers introduced leafy vegetables to their child but only half of mothers have introduced foods containing oils.Feeding with cup and spoon has become popular than the bottle feeding 
which is an improvement in proper feeding practices. Respiratory tract infections and gastroenteritis were common among children but nutritional status of child was not affected due to proper feeding practices during infections. Problems in feeding practices such as delay in introducing some essential food items into child's diet were associated with the poor nutritional status of children in this age group and there is a need of interventions to address this problem.

To improve the proper feeding practices, health education of mothers on breast feeding and complimentary feeding practices need to be strengthened and simple, understandable, proper nutritional massages through public health staff will be provided to the community. Behavioral change communication might be more useful than the information, education and communication method as the behavior and attitudes of the care givers affect their feeding practices.

\section{References}

[1] UNICEF. The state of world children, 2007 report.http://www.unicef.org/publications/files/The_State_of t he_Worlds_Children_2007_e.pdf

[2] Food and Agriculture organization. Annual report.1992

[3] Onis M, Blössner M, Borghi E, Frongillo EA, Morris R, Estimates of Global Prevalence of Childhood Underweight in 1990 and 2015.JAMA. 2004; 291(21):2600-2606. http://jama.jamanetwork.com/article.aspx?articleid=198842

[4] UNICEF.Improving child nutrition. The achievable omperative for global progress; 2013 http://data.unicef.org/corecode/uploads/document6/uploaded pdfs/corecode/NutritionReport_April2013_Final_29.pdf)

[5] MRI. Nutrition Report; 1998.

[6] Department of census and statistics. Demographic and Health Survey report; 2006

[7] WHO, World Health Organization. WHO. UNICEF, World Bank joint estimates, data sheet, 2014. Retrieved from who.int/nutgrowthdb/estimates

[8] Jesmin A, Yamamoto SS, Malik AA and Haque MD. Prevalence and Determinants of Chronic Malnutrition among Preschool Children: A Cross-sectional Study in Dhaka City, Bangladesh. J Health Popul Nutr. Oct 2011; 29(5): 494-499.

[9] Bhuriya A., Woksynalak B., De Soysa, et al. Socioeconomic Determinants of Childhood nutritional Status. Food and Nutrition Bulletin; 1986, (3), 3-7

[10] Powel LA, Grantham S. The Etiology of Nutritional Status and Development in Young Children in Kingston, Jamaica, American Journal of clinical nutrition;1985, 41, 22 -30

[11] Gopaldas T, Patel P, Bakshi U. Selected economic environmental, maternal and child factors, associated with nutritional status of infants and toddlers, Food and Nutrition Bulletin; 1988, 10(4), 29-34.

[12] Department of census and statistics, Ministry of Planning and Implementation in collaboration with Ministry of Health. Preliminary report of Demographic and Health Survey; 1993
[13] Weerasinghe C. Socio economic and cultural factors contributing to malnutrition, Dissertation for MSc Nutrition; 1981

[14] Kocturak T, Attained weight for age position and selected background, Journal of tropical pediatrics; 1988, 34, 244-247

[15] UNICEF. Situational Analysis of children and women in Sri Lanka; 1987.

[16] Knip M, Akerblom HK. Early nutrition and later diabetes risk. In: B.Koletzko, P.Dodds, M. Ashwell, H. Akerblom, Ed. Early nutrition its later consequences: 2005 new Koletzko ISBN 1402035349.pdf

[17] WHO. Complimentary feeding-family food for breast fed children. Geneva: 2000

[18] Wikramanayaka TW. Nutrition throughout the life cycle; 2007 $19,2-26$

[19] WHO. Global Strategy for infant and young child feeding Geneva: 2003. World Health Organization

[20] Jayatissa R., Hossain M, Nanayakkara L. Assessment of nutritional status and associated factors in Nothern province. Medical research institute in collaboration with UNICEF and Ministry of health, Sri Lanka; 2012

[21] UNICEF. UNICEF Status of children's nutrition in Sri Lanka; 2013

[22] Peiris TDR. and Wijesinghe DGN. Nutritional Status of fewer than 5 Year-Old Children and its Relationship with Maternal Nutrition Knowledge in Weeraketiya DS division of Sri Lanka. Tropical Agricultural ResearchVol.; 2010, 21(4): 330 - 339

[23] Ediriweera T, Samaranayaka TSP, Perera MSA, Sivayogan, Perceptions and experience related to childhood feeding practices. A peri urban experience .SriLankan Family Physician; 2005(26) pg34-37.

[24] Cai X., Wardlaw T, Brown, DW, Global trends in exclusive breastfeeding, International Breastfeeding Journal 2012, 7:12 doi: 10.1186/1746-435Retrieved from http://www.internationalbreastfeedingjournal.com/content/7/1/ 12

[25] UNICEF. Global database. Infant and young child feeding. Retrieved from data.unicef.org; 2014

[26] Fernando DN, Soysa PE, 1986. Factors influencing infant feeding patterns in Sri Lanka, Ceylon Medical Journal; 1986, 29(2), 81-88

[27] Ministry ofhealth . Food based dietery guidelines, nutrition unit Ministry of health in collaboration with WHO.2011.pg $62-66$

[28] Dubbagh A, Ebrahims GT, The preventable antecedents of child malnutrition.

[29] Gigulani ERG, Sebbin CF, Golden M et al. The malnourished children of the urban, squatter families, journal of Tropical Pediatrics. 1980, 26 (1), 139-143.

[30] Wikramanayaka TW, Gunawardena D G, Wikramasingha N. June,Factors influencing the nutritional status of infants and pre school children of the urban poor, Ceylon Journal of medical science; $1989,(01), 33-34$ 
[31] Nestle P S, Rathnayaka RMK. Nutrition and Health Status of Children, Nutrition and Poverty division, Ministry of policy Planning and Implementation, Sethsiripaya, Battaramulla; 1997,122

[32] Shumey A, Demissie M. , BerhaneY. Timely initiation of complementary feeding and associated factors among children aged 6 to 12 months in Northern Ethiopia: an institution-based cross-sectional study, BMC Public Health
2013,
13:1050
retrieved
from

[33] Tamiru D, Aragu D, Belachew T, Survey on the Introduction of Complementary Foods to Infants within the First Six Months and Associated Factors in Rural Communities of Jimma Arjo, International Journal of Nutrition and Food Sciences. Vol. 2, No. 2, 2013, pp. 77-84.doi: 10.11648/j.ijnfs.20130202.18 